\title{
Design and Implementation of a Comprehensive Evaluation Model for Shallow Groundwater Based on Matter Element Extension
}

\author{
Ding Ding ${ }^{1 *}$, Lin Zhang ${ }^{2}$, Junliang Liu $^{3}$, Feng Chen ${ }^{1}$, Xiurong $\mathrm{Si}^{1}$ \\ ${ }^{1}$ North China Institute of Aerospace Engineering, Langfang 065000, China \\ ${ }^{2}$ United Taize Environmental Technology Development Co., Ltd., Tianjin 300000, China \\ ${ }^{3}$ Urban and Rural Construction Institute, Hebei Agricultural University, Baoding 071000, China
}

Corresponding Author Email: jane860523@nciae.edu.cn

https://doi.org/10.18280/ijdne.150510

Received: 1 May 2020

Accepted: 28 August 2020

\section{Keywords:}

water quality evaluation, groundwater, matter element extension, comprehensive evaluation method

\begin{abstract}
Groundwater quality directly bears on the living quality, social progress, and economic growth. To rationally develop and utilize groundwater, it is important to scientifically evaluate the groundwater quality. Using the data of groundwater quality in Gu'an county, northern China's Hebei Province, this paper selects a total of 7 evaluation indices, namely, $\mathrm{Ca}^{2+}, \mathrm{Na}^{+}, \mathrm{Cl}^{-}, \mathrm{F}^{-}$, sulfate, salinity, and total hardness, and then sets up a comprehensive evaluation model based on matter element extension. The specific steps of the model were explained, including matter element definition, index weighting, construction of correlation function, and water quality evaluation. The evaluation results of our model were compared with those of the normative method: comprehensive evaluation method. The comparison shows that our method is reliable enough for evaluating the groundwater quality in the study area. The research results shed light on the formation and trend of water quality, the pollution state of water bodies, and scientific protection and utilization of water resources.
\end{abstract}

\section{INTRODUCTION}

The economic growth and social progress have stimulated the demand for high-quality water resources. Gu'an, a county in northern China's Hebei Province, is a severely waterdeficient area. The per-capita water resources are far below the internationally recognized standard for water shortage. The groundwater resources, all of which are freshwater, have been overexploited across the county. Due to the unreasonable exploitation and utilization of water resources, water pollution and other problems have become more and more serious. Against this backdrop, it is important to scientifically evaluate water quality, and understand the quality of water bodies in the county. The evaluation results will provide scientific basis for the protection of water environment, rationalize water exploitation and utilization, and promote the sustainable development of water resources [1-3].

Currently, water quality is mainly evaluated based on indices, matrix operation, or sample training. Among them, the matrix operation-based methods include fuzzy mathematics, grey system, and analytic hierarchy process (AHP). In water quality evaluation, the most typical sample training-based method is backpropagation neural network (BPNN). Overall, the fuzzy comprehensive evaluation (FCE) is the most widely used method for water quality evaluation. However, the FCE calculates membership based on the highest and lowest values, without considering the influence of the intermediate value. In some cases, the FCE might easily lose information, causing the evaluation results to deviate from the actual situation [4-8].

There are diverse evaluation indices for water quality. The evaluation result of a single index is not compatible with that of another index. These features conform to the basic principle of the matter element extension model. Therefore, this paper establishes a water quality evaluation model based on matter element extension, and applies the model to analyze the water quality in Gu'an county $[9,10]$.

\section{MATTER ELEMENT EXTENSION MODEL}

\subsection{Matter element extension}

Proposed by Chinese professor Cai Wen in the 1980s, matter element extension is a theoretical method that handles incompatible problems. It has been widely applied in various fields, such as new product conception and design, optimized decision-making, control, identification, and evaluation.

Matter element extension fully integrates matter element analysis with extension set method. The latter is a mathematical tool for matter element analysis. By extension set method, the fuzzy set is extended from the interval $[0,1]$ to $(-\infty,+\infty)$ on the real number axis, and the correlation of the extension set of matter elements is expressed algebraically to quantify the incompatible problem. In this way, matter element extension can objectively reflect the situation in the real world $[11,12]$.

\subsection{Basic contents}

\subsubsection{Matter element}

Matter element is the abbreviation of the three basic elements of each matter, namely, name, characteristic, and value. Let $M$ be the target matter, $C$ be the characteristic of $M$, and $V$ be the $C$ value of $M$. Then, the matter element can be 
expressed as an ordered triple $R=(M, C, V)$. If matter $\mathrm{M}$ has $\mathrm{n}$ features $c_{1}, c_{2}, \ldots, c_{n}$, whose values are $v_{1}, v_{2}, \ldots, v_{n}$, then an $n$ dimensional matter element matrix can be defined:

$$
R(x)=\left[\begin{array}{ccc}
M & c_{1} & v_{1} \\
& c_{2} & v_{2} \\
& \ldots & \\
& c_{n} & v_{n}
\end{array}\right]
$$

\subsubsection{Classic domain and node domain}

The matter element matrix composed of the characteristics of a matter and their value ranges is called the classic domain $R_{0}$ :

$$
R(x)=\left[\begin{array}{ccc}
M & c_{1} & {\left[a_{01}, b_{01}\right]} \\
& c_{2} & {\left[a_{02}, b_{02}\right]} \\
& \cdots & \\
& c_{n} & {\left[a_{0 n}, b_{0 n}\right]}
\end{array}\right]
$$

where, $c_{1}, c_{2}, \ldots, c_{n}$ are characteristics of matter element; $a_{0 i}$ and $b_{0 i}$ are the lower and upper limits of the value of classic domain characteristic $X_{0 i}$, respectively; $i=1,2, \ldots, n$.

The matter element matrix, the matter that can be converted into classic matter element, the characteristics of the matter, and the extended value ranges of the characteristics can be combined into a new matter element matrix called the node domain $R_{c}$ :

$$
R(x)=\left[\begin{array}{ccc}
M_{c} & c_{1} & {\left[a_{c 1}, b_{c 1}\right]} \\
& c_{2} & {\left[a_{c 2}, b_{c 2}\right]} \\
& \ldots & \\
& c_{n} & {\left[a_{c n}, b_{c n}\right]}
\end{array}\right]
$$

where, $c_{1}, c_{2}, \ldots, c_{n}$ are characteristics; $a_{c i}$ and $b_{c i}$ are the lower and upper limits of the value of node domain characteristic $X_{c i}$, respectively; $i=1,2, \ldots, n$. Obviously, $X_{0 i} \in X_{c i}$.

\subsubsection{Moment}

Moment refers to the distance between the point ${ }_{x j}$ and the interval $X_{i j}=\left(a_{i j}, b_{i j}\right)$ on the real number axis:

$$
\rho\left(x_{j}, X_{i j}\right)=\left|x_{j}-1 / 2\left(a_{i j}+b_{i j}\right)\right|-1 / 2\left(b_{i j}-a_{i j}\right)
$$

where, $i=1,2, \ldots, m ; j=1,2, \ldots, n$.

Similarly, the moment between real number point $x_{j}$ and node domain interval $X_{p j}=\left(a_{p j}, b_{p j}\right)$ is the node domain moment:

$$
\rho\left(x_{j}, X_{p j}\right)=\left|x_{j}-1 / 2\left(a_{p j}+b_{p j}\right)\right|-1 / 2\left(b_{p j}-a_{p j}\right)
$$

where, $j=1,2, \ldots n$.

\subsubsection{Correlation function $k(x)$}

The correlation function $k(x)$ represents the membership of the evaluation object to a criterion. The value of the function is the correlation. The correlation function is selected based on the characteristics of the object and the extension set theory. To clearly disclose the membership, it is necessary to choose a suitable correlation function for the specific matter. In this paper, the evaluation object is groundwater quality. Thus, the correlation function can be selected as:

$$
k i(x j)=\left\{\begin{array}{lr}
-\rho\left(x_{j}, X_{i j}\right) /\left|X_{i j}\right| & x_{j} \in X_{i j} \\
\rho\left(x_{j}, X_{i j}\right) /\left[\rho\left(x_{j}, X_{i j}\right)-\rho\left(x_{j}, X_{i j}\right)\right] & x_{j} \notin X_{i j}
\end{array}\right.
$$

where, $i=1,2, \ldots, m ; j=1,2, \ldots, n ;\left|X_{i j}\right|=\left|a_{i j}-b_{i j}\right|$.

2.2.5 Weight coefficient aj and comprehensive correlation $k j(p)$

To realize comprehensive evaluation, different evaluation indices should be assigned different weights, according to their impacts on water quality. The weight can be calculated in the light of the actual situation. Different formulas should be adopted to compute the weight of each index based on the evaluation objective. The common ways to calculate weight coefficients include top-down system analysis, expert scoring, AHP, pollution contribution method, correlation function method, etc. The pollution contribution method was chosen for this research. Since the groundwater quality is negatively correlated with the measured value of each index, the selected method was improved as:

$$
a_{j}=\frac{\frac{x_{j}}{\bar{s}_{j}}}{\sum_{j=1}^{n} \frac{x_{j}}{\bar{s}_{j}}}
$$

where, $x_{j}$ is the measured value of each level $j$ indices; $s_{j}$ is the mean value of level $j$ indices; $a_{j}$ is the weight of level $j$ indices.

The comprehensive correlation the product of the correlation e and the weight coefficient:

$$
k_{j}(p)=\sum_{j=1}^{n} a_{j} \times k_{j}\left(x_{j}\right)
$$

where, $k_{j}(p)$ is the comprehensive correlation of object $p$ with respect to level $j$.

The comprehensive correlation demonstrates the water quality from two aspects: the membership, and the impact of each index on the entire water body. Therefore, this parameter provides an objective and accurate evaluation of the object.

If $k_{j}=\max \left[k_{j}(p)\right]$, then object $\mathrm{p}$ belongs to level $j$. In this way, the quality of the target water body can be determined.

\subsubsection{Extension index $J$}

The extension index $\mathrm{j}$ reflects how much the object is biased to the adjacent level:

$$
\begin{gathered}
\bar{K}_{j}(p)=\frac{K_{j}(p)-\min K_{j}(p)}{\max K_{j}(p)-\min K_{j}(p)} \\
J=\sum_{j=1}^{m} j \bar{K}_{i}(p) / \sum_{j=1}^{m} \bar{K}_{j}(p)
\end{gathered}
$$

where, $K_{j}(p)$ is the correlation; $j$ is the evaluation level [13-16].

\section{MODEL APPLICATION}

\subsection{Index selection}

The evaluation object is the water quality of three fixed monitoring wells in Gu'an county. To make the evaluation more realistic, a total of seven indices were selected, namely, 
$\mathrm{Ca}^{2+}, \mathrm{Na}^{+}, \mathrm{Cl}^{-}, \mathrm{F}^{-}$, sulfate, salinity, and total hardness, according to the cumulative out-of-limit frequency of various factors in groundwater samples in Gu'an, the impacts of each pollutant on water quality, and the health damage of these pollutants [17].

\subsection{Evaluation criteria}

The evaluation criteria were prepared based on levels I-V in the Standard for Groundwater Quality (GB/T14848-2017), in which level V has no upper limit. Since the samples contain no factor that seriously exceeds the limit, level V was removed, and levels I-IV were adopted as the evaluation criteria (Table $1)$.

Table 1. The evaluation criteria (unit: $\mathrm{mg} / \mathrm{L}$ )

\begin{tabular}{cccccccc}
\hline Level & $\mathbf{C a}^{2+}$ & $\mathbf{C l}^{-}$ & $\mathbf{N a}^{+}$ & $\mathbf{S O}_{4}{ }^{2-}$ & $\mathbf{F}^{-}$ & Salinity & $\begin{array}{c}\text { Total } \\
\text { hardness }\end{array}$ \\
\hline I & 50 & 50 & 100 & 50 & 1 & 300 & 150 \\
II & 100 & 150 & 150 & 150 & 1 & 500 & 300 \\
III & 150 & 250 & 200 & 250 & 1 & 1000 & 450 \\
IV & 200 & 350 & 400 & 350 & 2 & 2000 & 650 \\
\hline
\end{tabular}

\subsection{Water quality evaluation and result analysis}

According to the definitions of classic domain and node domain, classic domains $R_{01}, R_{02}, R_{03}$, and $R_{04}$ and node domain $R_{c}$ can be derived from Table 1 . The matter element matrices $R_{1}, R_{2}$, and $R_{3}$ of the evaluation samples can be obtained from the observed data.

$$
\begin{array}{r}
\mathrm{R}_{01}=\left(\begin{array}{cc}
\mathrm{Ca}^{2+} & \langle 0,50\rangle \\
\mathrm{Cl}^{-} & \langle 0,50\rangle \\
\mathrm{Na}^{+} & \langle 0,100\rangle \\
\mathrm{S}_{4}^{2-} & \langle 0,50\rangle \\
\mathrm{F}^{-} & \langle 0,1\rangle \\
\mathrm{TDS} & \langle 0,300\rangle \\
\mathrm{TH} & \langle 0,150\rangle
\end{array}\right), R_{02}=\left(\begin{array}{cc}
\mathrm{Ca}^{2+} & \langle 50,100\rangle \\
\mathrm{Cl}^{-} & \langle 50,150\rangle \\
\mathrm{Na}^{+} & \langle 100,150\rangle \\
\mathrm{S}_{4}^{2-} & \langle 50,150\rangle \\
\mathrm{F}^{-} & \langle 1,1\rangle \\
\mathrm{TDS} & \langle 300,500\rangle \\
\mathrm{TH} & \langle 150,300\rangle
\end{array}\right), \\
R_{03}=\left(\begin{array}{cc}
\mathrm{Ca}^{2+} & \langle 100,150\rangle \\
\mathrm{Cl}^{-} & \langle 150,250\rangle \\
\mathrm{Na}^{+} & \langle 150,200\rangle \\
\mathrm{S}_{4}^{2-} & \langle 150,250\rangle \\
\mathrm{F}^{-} & \langle 1,1\rangle \\
\mathrm{TDS} & \langle 500,1000\rangle \\
\mathrm{TH} & \langle 300,450\rangle
\end{array}\right), R_{04}=\left(\begin{array}{cc}
\mathrm{Ca}^{2+} & \langle 150,200\rangle \\
\mathrm{Cl}^{-} & \langle 250,350\rangle \\
\mathrm{Na}^{+} & \langle 200,100\rangle \\
\mathrm{SO}_{4}^{2-} & \langle 250,350\rangle \\
\mathrm{F}^{-} & \langle 1,2\rangle \\
\mathrm{TDS} & \langle 1000,2000\rangle \\
\mathrm{TH} & \langle 450,650\rangle
\end{array}\right),
\end{array}
$$

$$
R c=\left(\begin{array}{cc}
\mathrm{I}-\mathrm{IV} \mathrm{Ca} & \langle 50,100\rangle \\
\mathrm{Cl}^{-} & \langle 50,150\rangle \\
\mathrm{Na}^{+} & \langle 100,150\rangle \\
\mathrm{S}_{4}^{2-} & \langle 250,350\rangle \\
\mathrm{F}^{-} & \langle 1,1\rangle \\
\mathrm{TDS} & \langle 300,500\rangle \\
\mathrm{TH} & \langle 150,300\rangle
\end{array}\right), R_{1}=\left(\begin{array}{cc}
\mathrm{Ca}^{2+} & 56.1 \\
\mathrm{Cl}^{-} & 43.9 \\
\mathrm{Na}^{+} & 58 \\
\mathrm{~S}_{4}^{2-} & 37.4 \\
\mathrm{~F}^{-} & 0.45 \\
\mathrm{TDS} & 446 \\
\mathrm{TH} & 271
\end{array}\right) .
$$

The above matter element matrices, node domain, and classic domains were substituted into formulas (1)-(3) to find the correlations of each evaluation index with the levels of water quality (Table 2). The weight coefficient of each index was computed by formula (5) (Table 3 ). Then, the correlations and weight coefficients were substituted into formula (4) to obtain the comprehensive correlation of each sample with each

\begin{tabular}{|c|c|c|c|c|}
\hline Index $\quad$ Level & I & II & III & IV \\
\hline $\mathrm{Ca}^{2+}$ & -0.09807 & 0.122 & -0.439 & -0.626 \\
\hline $\mathrm{Cl}^{-}$ & 0.122 & -0.122 & -0.70733 & -0.8244 \\
\hline $\mathrm{Na}^{+}$ & 0.42 & -0.42 & -0.61333 & -0.71 \\
\hline $\mathrm{SO}_{4}{ }^{2-}$ & 0.252 & -0.252 & -0.75067 & -0.8504 \\
\hline $\mathrm{F}^{-}$ & 0.45 & -0.55 & -0.55 & -0.55 \\
\hline TDS & -0.24662 & 0.27 & -0.108 & -0.554 \\
\hline $\mathrm{TH}$ & -0.30867 & 0.193333 & -0.09667 & -0.39778 \\
\hline
\end{tabular}
level.

Table 2. The correlations of indices in well 1\#

Table 3. The weight coefficient of each index in well 1\#

\begin{tabular}{ccccc}
\hline Index & $\mathbf{C a}^{\mathbf{2 +}}$ & $\mathbf{C l}^{-}$ & $\mathbf{N a}^{+}$ & $\mathbf{S O}_{4}{ }^{2-}$ \\
\hline Weight & 0.1689 & 0.0826 & 0.1027 & 0.0704 \\
Index & $\mathrm{F}^{-}$ & TDS & TH & \\
Weight & 0.1355 & 0.1767 & 0.2632 & \\
\hline
\end{tabular}

Through the above steps, the comprehensive correlations for all the three wells were calculated by matter element extension method. The results of the three wells were ranked in descending order to find the one with the best water quality (Table 4).

As shown in Table 4, the water qualities of all three wells belong to level I, indicating that the groundwater is of good quality, and fit for domestic, industrial, and agricultural uses. Substituting the above results into formulas (6) and (7), the extension index $\mathrm{J}$ of each well can be obtained to reflect the trend of water quality (Table 5).

Table 4. The evaluated level of each well

\begin{tabular}{cccccc}
\hline Well & \multicolumn{4}{c}{ Water quality } & Evaluated \\
\cline { 2 - 5 } number & I & II & III & IV & level \\
\hline 01 & -0.00946 & -0.02628 & -0.36746 & -0.58372 & I \\
02 & 0.17513 & -0.34520 & -0.76427 & -0.76427 & I \\
03 & 0.29318 & -0.48369 & -0.88786 & -0.80851 & I \\
\hline
\end{tabular}

Table 5. The extension index $\mathrm{J}$ of each well

\begin{tabular}{cccc}
\hline Well number & 01 & 02 & 03 \\
\hline Extension index & 1.7344 & 1.3085 & 1.3645 \\
\hline
\end{tabular}

As shown in Table 5, although the water qualities of all three wells belong to level I, the water qualities are poised to degrade to level II. Hence, the groundwater in the study area is deteriorating. More attention should be paid to curve the deterioration. 


\section{NORMATIVE EVALUATION}

To verify the correctness of the evaluation results, the comprehensive evaluation method, which is recommended in the Standard for Groundwater Quality (GB/T14848-2017), was selected to evaluate the water quality of each well again. By this normative evaluation method, the worst level evaluated by a single index is taken as the final level, and the indices of the worst category are identified $[18,19]$. Table 6 shows the evaluation result on each index and the comprehensive evaluation index; Table 7 compares the results of our method and the normative method.

Table 6. The levels evaluated by comprehensive evaluation method

\begin{tabular}{cccccccc}
\hline Index & $\mathrm{Ca}^{2+}$ & $\mathrm{Cl}^{-}$ & $\mathrm{Na}^{+}$ & $\mathrm{SO}_{4}^{2-}$ & $\mathrm{F}^{-}$ & $\mathrm{TDS}$ & $\mathrm{TH}$ \\
\hline 01 & II & I & I & I & I & II & II \\
02 & I & I & I & I & I & I & I \\
03 & I & I & I & I & I & I & I \\
\hline
\end{tabular}

As shown in Table 6, the evaluation results of each index indicate that level II took up $42.9 \%$ of the evaluated results on the groundwater of well 1\#. Taking the worst level as the final level, the groundwater of well 1\# belong to level II. Similarly, it can be seen that the groundwaters in wells $2 \#$ and $3 \#$ both belong to level I.

Table 7. The results of our method and the normative method

\begin{tabular}{ccc}
\hline Well number & Our method & Normative method \\
\hline 01 & I & II \\
02 & I & I \\
03 & I & I \\
\hline
\end{tabular}

As shown in Table 7, our method and normative method agreed in $83.3 \%$ of the evaluated levels. The $16.7 \%$ difference comes from the disparity between the two methods in the value ranges of indices like $\mathrm{Ca}^{2+}$, total dissolved solids (TDS), and total hardness.

The comparative analysis confirms the suitability and reliability of our matter element extension model in groundwater quality evaluation. The proposed model can be applied to evaluate the groundwater in similar areas.

\section{CONCLUSIONS}

(1) This paper proposes a comprehensive water quality evaluation model based on matter element extension. With simple concepts, the proposed model can make objective evaluations through simple operations. The model indices, namely, comprehensive correlation and extension index, reflect the absoluteness and relativity of the evaluated level, and help to quantify the trend of water quality in the evaluation samples [20].

(2) The proposed model was applied to evaluate the shallow groundwater samples from three wells in Gu'an county, using seven evaluation indices. The evaluation results were highly similar to those obtained by the comprehensive evaluation method. This means the proposed model is reliable enough for comprehensive evaluation of water quality.

(3) Through the evaluations by our method and normative method, the shallow groundwater in the study area has a good quality, and applies to drinking and irrigation purposes. The low natural background value indicates the limited influence of human activities. Therefore, the groundwater quality in the study area should be further protected in future. The groundwater resources must be developed and utilized rationally. Efforts should be made to minimize or eliminate groundwater pollution.

\section{ACKNOWLEDGEMENTS}

This paper was supported by the project of North China Institute of Aerospace Engineering (Grant No.: KY-2020-15); and the project of Hebei Education Department (Grant No.: Z2020214) and the project of Talent Engineering Training in Hebei Province (Grant No.: A201901065).

\section{REFERENCES}

[1] Pokhrel, S.R., Chhipi-Shrestha, G., Hager, J., Rodriguez, M.J., Hewage, K., Sadiq, R. (2020). Performance assessment framework for small water systems: Case study in British Columbia. Journal of Water Resources Planning and Management, 146(12): 05020025. https://doi.org/10.1061/(ASCE)WR.1943-5452.0001297

[2] Latchmore, T., Hynds, P., Brown, R.S., SchusterWallace, C., Dickson-Anderson, S., McDermott, K., Majury, A. (2020). Analysis of a large spatiotemporal groundwater quality dataset, Ontario 2010-2017: Informing human health risk assessment and testing guidance for private drinking water wells. Science of the Total Environment, 738: 140382. https://doi.org/10.1016/j.scitotenv.2020.140382

[3] Kim, K.B., Jung, M.K., Tsang, Y.F., Kwon, H.H. (2020). Stochastic modeling of chlorophyll-a for probabilistic assessment and monitoring of algae blooms in the Lower Nakdong River, South Korea. Journal of Hazardous Materials, $\quad 400$ : 123066. https://doi.org/10.1016/j.jhazmat.2020.123066

[4] Jamal, R., Mubarak, S., Sahulka, S.Q., Kori, J.A., Tajammul, A., Ahmed, J., Mahar, R.B., Olsen, M.S., Goel, R., Weidhaas, J. (2020). Informing water distribution line rehabilitation through quantitative microbial risk assessment. Science of the Total Environment, 793: 140021. https://doi.org/10.1016/j.scitotenv.2020.140021

[5] Fang, Y., Zheng, T., Zheng, X., Peng, H., Wang, H., Xin, J., Zhang, B. (2020). Assessment of the hydrodynamics role for groundwater quality using an integration of GIS, water quality index and multivariate statistical techniques. Journal of Environmental Management, 273: 111185. https://doi.org/10.1016/j.jenvman.2020.111185

[6] Schuwirth, N. (2020). Towards an integrated surface water quality assessment: Aggregation over multiple pollutants and time. Water Research, 186: 116330. https://doi.org/10.1016/j.watres.2020.116330

[7] Hasan, M.N., Rahman, K., Bhuia, M.R. (2020). Assessment of ground water quality in the vicinity of Sylhet City, Bangladesh: a multivariate analysis. Sustainable Water Resources Management, 6(5): 88. https://doi.org/10.1007/s40899-020-00448-x

[8] Deep, A., Gupta, V., Bisht, L., Kumar, R. (2020). Application of WQI for water quality assessment of high- 
altitude snow-fed sacred Lake Hemkund, Garhwal Himalaya. Sustainable Water Resources Management, 6(5): 89. https://doi.org/10.1007/s40899-020-00449-w

[9] Wong, Y.J., Shimizu, Y., He, K., Sulaiman, N.M.N. (2020). Comparison among different ASEAN water quality indices for the assessment of the spatial variation of surface water quality in the Selangor river basin, Malaysia. Environmental Monitoring and Assessment, 192(10): 644. https://doi.org/10.1007/s10661-02008543-4

[10] Ghobadi, A., Cheraghi, M., Sobhanardakani, S., Lorestani, B., Merrikhpour, H. (2020). Hydrogeochemical characteristics, temporal, and spatial variations for evaluation of groundwater quality of Hamedan-Bahar Plain as a major agricultural region, West of Iran. Environmental Earth Sciences, 79(18): 428. https://doi.org/10.1007/s12665-020-09177-y

[11] Yuan, J., Wang, J.C., Qian, B. (2020). Optimization of water quality evaluation method in Three Gorges Reservoir area under different hydrological conditions. Proceedings of the International Association of Hydrological Sciences, 383: 347-353. https://doi.org/10.5194/piahs-383-347-2020

[12] Orak, E., Akkoyunlu, A., Can, Z.S. (2020). Assessment of water quality classes using self-organizing map and fuzzy C-means clustering methods in Ergene River, Turkey. Environmental Monitoring and Assessment, 192(10): 638. https://doi.org/10.1007/s10661-02008560-3

[13] Sheikhi, S., Faraji, Z., Aslani, H. (2020). Arsenic health risk assessment and the evaluation of groundwater quality using GWQI and multivariate statistical analysis in rural areas, Hashtroud, Iran. Environmental Science and Pollution Research, 32929669. https://doi.org/10.1007/s11356-020-10710-6

[14] Saal, I., Bouchelouche, D., Hamache, C., Arab, A. (2020). Evaluation of the surface water quality in the Kebir-
Rhumel catchment area (northeast Algeria) using biotic indices and physico-chemical analyses. Environmental Science and Pollution Research, 32865679. https://doi.org/10.1007/s11356-020-10598-2

[15] Yuan, Z., Li, Q., Ma, X., Han, M. (2020). Assessment of heavy metals contamination and water quality characterization in the Nanming River, Guizhou Province. Environmental Geochemistry and Health, 32910330. https://doi.org/10.1007/s10653-020-00710-3

[16] Norouzi, H., Moghaddam, A.A. (2020). Groundwater quality assessment using random forest method based on groundwater quality indices (case study: Miandoab plain aquifer, NW of Iran). Arabian Journal of Geosciences, 13(18): 912. https://doi.org/10.1007/s12517-020-059048

[17] Imbulana, S., Oguma, K., Takizawa, S. (2020). Evaluation of groundwater quality and reverse osmosis water treatment plants in the endemic areas of Chronic Kidney Disease of Unknown Etiology (CKDu) in Sri Lanka. Science of The Total Environment, 745: 140716. https://doi.org/10.1016/j.scitotenv.2020.140716

[18] Wijeyaratne, W.M.D.N., Nanayakkara, D.B.M. (2020). Monitoring of water quality variation trends in a tropical urban wetland system located within a Ramsar wetland city: A GIS and phytoplankton based assessment. Environmental Nanotechnology, Monitoring \& Management, $\quad 14: \quad 100323$. https://doi.org/10.1016/j.enmm.2020.100323

[19] Leng, L., Mao, X., Jia, H., Xu, T., Chen, A.S., Yin, D., $\mathrm{Fu}, \mathrm{G}$. (2020). Performance assessment of coupled greengrey-blue systems for Sponge City construction. Science of the Total Environment, 728: 138608. https://doi.org/10.1016/j.scitotenv.2020.138608

[20] Judran, N.H., Kumar, A. (2020). Evaluation of water quality of Al-Gharraf River using the water quality index (WQI). Modeling Earth Systems and Environment, 6(3): 1581-1588. https://doi.org/10.1007/s40808-020-00775-0 